\title{
Changes in sodium appetite evoked by lesions of the commissural nucleus of the tractus solitarius
}

\author{
C.A. Ogihara1, G.H.M. Schoorlemmer ${ }^{1}$, E. Colombari ${ }^{1,2}$ and M.A. Sato ${ }^{1,2}$ \\ ${ }^{1}$ Departamento de Fisiologia, Escola Paulista de Medicina, Universidade Federal de São Paulo, \\ São Paulo, SP, Brasil \\ ${ }^{2}$ Departamento de Fisiologia, Faculdade de Medicina do ABC, Santo André, SP, Brasil \\ Correspondence to: M.A. Sato, Departamento de Fisiologia, Faculdade de Medicina do ABC, Av. Lauro \\ Gomes, 2000, 09060-870 Santo André, SP, Brasil \\ Fax: +55-11-4993-5427. E-mail: monica.akemi.sato@gmail.com
}

\begin{abstract}
Ablation of the area postrema/caudal nucleus of the tractus solitarius (NTS) complex increases sodium intake, but the effect of selective lesions of the caudal NTS is not known. We measured depletion-induced sodium intake in rats with electrolytic lesions of the commissural NTS that spared the area postrema. One day after the lesion, rats were depleted of sodium with furosemide ( $10 \mathrm{mg} / \mathrm{kg}$ body weight, $s c$ ) and then had access to water and a sodium-deficient diet for $24 \mathrm{~h}$ when $1.8 \% \mathrm{NaCl}$ was offered. Water and saline intakes were measured for $2 \mathrm{~h}$. Saline intake was higher in lesioned than in sham-lesioned rats (mean \pm SEM: $20 \pm$ 2 vs $11 \pm 3 \mathrm{~mL} / 2 \mathrm{~h}, \mathrm{P}<0.05, \mathrm{~N}=6-7)$. Saline intake remained elevated in lesioned rats when the tests were repeated 6 and 14 days after the lesion, and water intake in these two tests was increased as well. Water intake seemed to be secondary to saline intake both in lesioned and in sham-lesioned rats. A second group of rats was offered $10 \%$ sucrose for $2 \mathrm{~h} /$ day before and 2,7 , and 15 days after lesion. Sucrose intake in lesioned rats was higher than in sham-lesioned rats only 7 days after lesioning. $\mathrm{A}$ possible explanation for the increased saline intake in rats with commissural NTS lesions could be a reduced gastrointestinal feedback inhibition. The commissural NTS is probably part of a pathway for inhibitory control of sodium intake that also involves the area postrema and the parabrachial nucleus.
\end{abstract}

Key words: Nucleus of the solitary tract; Sodium appetite; Sucrose; Furosemide

Research supported by FAPESP, Núcleo de Estudo, Pesquisa e Assessoria à Saúde, Faculdade de Medicina do ABC (NEPAS, FMABC). C.A. Ogihara was the recipient of a Master's scholarship from CAPES.

Received May 9, 2008. Accepted April 13, 2009

\section{Introduction}

Sodium depletion stimulates the intake of salty solutions. Depletion-induced sodium appetite depends on both the forebrain and the midbrain. Sodium depletion stimulates the production of angiotensin II, which acts on the vascular organ of the lamina terminalis and the subfornical organ in the forebrain to stimulate salt intake. In the midbrain, the lateral parabrachial nucleus can powerfully inhibit sodium intake $(1,2)$.

Hindbrain areas, especially the area postrema and the adjacent nucleus of the solitary tract (NTS), also affect the intake of sodium, but their function is less clear. This region receives visceral and cardiovascular vagal information, and it has been suggested that lesions in this area affect fluid intake by disrupting feedback inhibition (3). Lesions of the area postrema stimulate sodium intake even in animals that are not sodium depleted (4-6). However, neighboring regions may have opposite effects on sodium intake. For example, area postrema lesions that include parts of the NTS are less effective in stimulating saline intake than area postrema lesions that leave the NTS intact (6).

We hypothesized that the caudal (commissural) NTS may also affect sodium intake. The commissural NTS is 
the first relay in the central nervous system for chemoreceptor afferents, but also contains axons of neurons from the rostral NTS, which receives afferents arising from the gastrointestinal tract and gustatory axons from the facial, glossopharyngeal, and vagus nerves (7-9). Gustatory neurons in the anterior NTS project to the parabrachial nucleus (8-11). The parabrachial nucleus sends gustatory information to other structures known to be involved in sodium appetite, including the central nucleus of the amygdala (12).

The present study was designed to investigate the effect of lesions restricted to the commissural NTS on sodium appetite. Because the cardiovascular effects of commissural NTS lesions vary with time (13), we studied the effects of the lesions at various times. In order to evaluate whether these lesions specifically affect sodium intake or also affect other types of fluid intake, we measured the effect of the lesions on need-free intake of a sucrose solution.

\section{Material and Methods}

\section{Animals \\ Male Wistar rats weighing $350-400 \mathrm{~g}$ at the beginning of the experiments were used. The rats were housed individually in metabolic cages in a temperature-controlled room $\left(22^{\circ} \mathrm{C}\right)$ with a $12-\mathrm{h}$ light/dark cycle (lights on at 7:00 am), and had free access to rat chow and water. All procedures were in accordance with the code of practice for the care and use of animals for scientific purposes of the Brazilian College of Animal Experimentation (COBEA), and were approved by the Animal Experimentation Ethics Committee of the Federal University of São Paulo.}

\section{Sodium depletion and sodium appetite test}

Rats received an $s c$ injection of furosemide, $10 \mathrm{mg} / \mathrm{kg}$ body weight (10 mg/mL; Lasix, Aventis, Brazil). During the next $24 \mathrm{~h}$, drinking water remained available, and the regular chow was replaced with a low-sodium diet (corn meal). Then, the rats were allowed to drink for $2 \mathrm{~h}$ from graduated tubes containing water and $1.8 \% \mathrm{NaCl}$. Water and saline intakes were measured at 30,60, 90, and 120 $\min$.

\section{Brain lesions}

Rats were anesthetized with ketamine $(50 \mathrm{mg} / \mathrm{kg}$ body weight, ip; Dopalen, Vetbrands, Brazil) and xylazine (10 $\mathrm{mg} / \mathrm{kg}$ body weight, im; Anasedan, Vetbrands) and placed in a stereotaxic apparatus (960, DKI, USA) with the incisor bar positioned $11 \mathrm{~mm}$ below the interaural line. The skin was incised from a point just rostral to the occipital crest to the midcervical region, and the muscles were dissected to expose the atlanto-occipital membrane. This membrane and the underlying dura mater and arachnoid membranes were incised to expose the dorsal surface of the medulla. The area postrema was visualized with a surgical microscope. A Teflon-insulated tungsten electrode $(0.25 \mathrm{~mm}, \mathrm{~A}-$ M Systems, USA) was placed in the commissural NTS (on the midline, $0.1 \mathrm{~mm}$ posterior to the area postrema, and 0.5 $\mathrm{mm}$ below the dorsal surface of the medulla). Lesions were produced by passing a 3-mA current for $3 \mathrm{~s}$, using a constant current source (model EL-0502, Insight Equipamentos Científicos, Brazil), with the electrode connected to the negative terminal of the current source. Sham rats were subjected to the same surgical procedure but no electric current was passed. Muscle and skin were closed with sutures and a prophylactic injection of antibiotic $(0.2$ $\mathrm{mL} \mathrm{im}$, veterinary pentabiotic for small animals $2000 \mathrm{U} / \mathrm{mL}$; Fort Dodge, Brazil) was given.

\section{Histological analysis}

At the end of the experiments, the rats were sacrificed with an overdose of urethane ( $2 \mathrm{~g} / \mathrm{kg}$ ip; Sigma, USA) and perfused through the heart with $60 \mathrm{~mL} 10 \%$ formalin. The brain stem was removed and stored in $10 \%$ formalin for 48 h. Serial coronal 40- $\mu \mathrm{m}$ sections were cut with a freezing microtome and sections containing the lesion site were mounted, stained with neutral red (Sigma) and examined under a light microscope.

\section{Statistical analysis}

Data are reported as means \pm SEM. Data were analyzed by two-way analysis of variance (ANOVA). Differences between groups at each time were analyzed by the Tukey post hoc test. The level of significance was set at $P$ $<0.05$.

\section{Experimental protocols}

To measure the effect of commissural NTS lesions on sodium appetite we used 7 lesioned rats and 6 shamlesioned rats. All rats were injected with furosemide 7 days before surgery. The same rats received furosemide again 1,6 , and 14 days after surgery. Sodium appetite was measured $24 \mathrm{~h}$ after each furosemide injection in a twobottle test as described in Material and Methods.

To measure the effect of the lesions on sucrose intake, a different group of rats with permanent access to water was allowed to drink $10 \%$ sucrose from a graduated tube for $2 \mathrm{~h}$ /day (from 12:00 am to 2:00 pm) for 5 days. Intakes of sucrose and water were measured at 30,60, 90, and 120 min on the 5 th day. On the 6 th day, rats were submitted randomly to commissural NTS lesions $(N=5)$ or sham 
lesions $(N=5)$. Sucrose was offered again to these rats 2 , 7 , and 15 days after lesioning, and water and sucrose intakes were measured as before.

\section{Results}

Post-mortem analysis showed that lesions of the commissural NTS were located on the midline above the central canal and extended from the level of the obex to $\sim 1 \mathrm{~mm}$
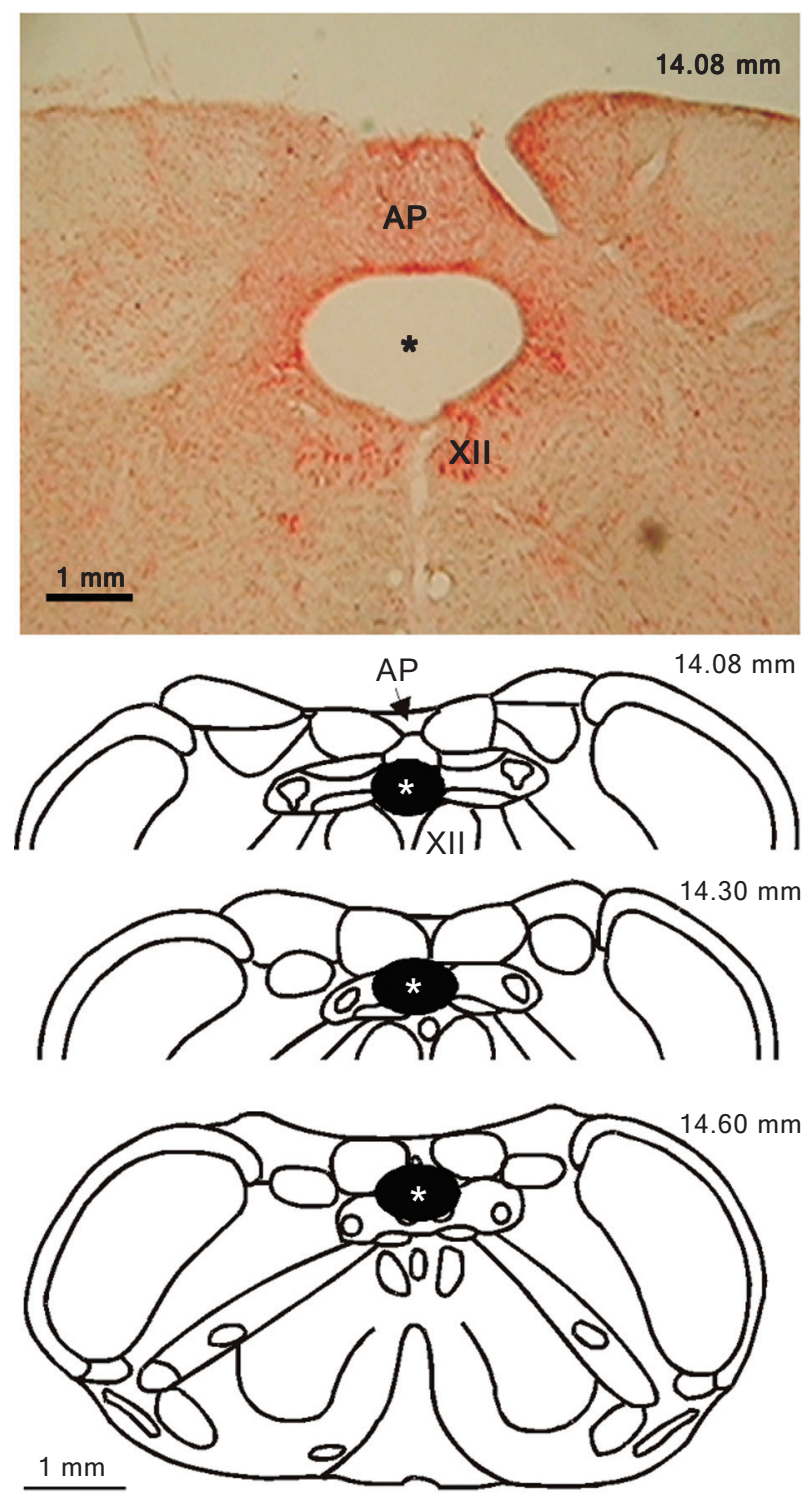

Figure 1. Photomicrograph of a coronal section from the brain stem showing a typical example of a commissural nucleus of the tractus solitarius lesion (asterisk) and diagrams showing the rostral-caudal extension of the lesion from bregma. AP $=$ area postrema; XII = hypoglossal nucleus. caudal to the obex (Figure 1). Lesions virtually destroyed the commissural NTS completely but did not affect the area postrema or lateral regions of the NTS. The extent of the lesions was similar to that observed in our earlier studies (13-16). Only rats whose lesion sites were located in the commissural NTS were considered for data analysis. Seven from a total of 10 lesioned rats were used for data analysis in the sodium appetite group. Five from 8 lesioned rats were included for data analysis in the sucrose intake group.

Need-induced intakes of $1.8 \% \mathrm{NaCl}$ and water were measured in two-bottle tests both before and after lesioning the commissural NTS. In the pre-lesion test, sodium-depleted experimental and control rats drank similar amounts of saline. After lesion, saline intake was larger in lesioned rats than in sham-lesioned controls (Figure 2). This difference was seen already 2 days after lesion $\left(F_{1,40}=10.8, P\right.$ $<0.01$ ), and continued until the end of the experiment, 15 days after lesion $\left(F_{1,44}=20.4, P<0.001\right)$.

Sodium-depleted rats drank little water, especially during the first half hour of the test. In the pre-lesion test, water intake was similar in the control and experimental groups. Two days after the lesion, water intake was similar in lesioned and sham-lesioned rats, but in later tests the lesioned rats drank more water than sham-lesioned con-

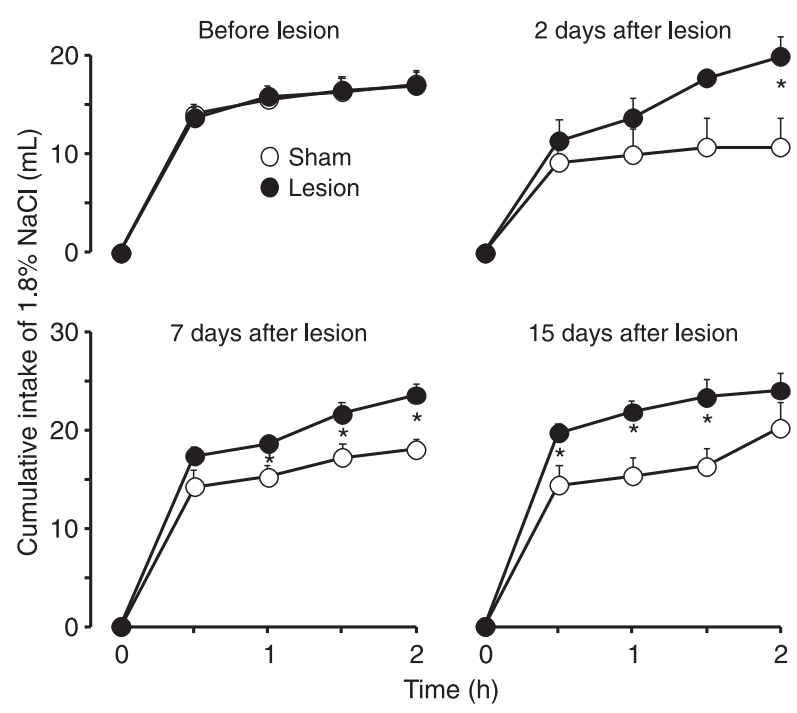

Figure 2. Cumulative intake of $1.8 \% \mathrm{NaCl}$ by sodium-depleted rats before surgery, and 2, 7 , and 15 days after commissural nucleus of the tractus solitarius lesions or sham lesions. Data are reported as means \pm SEM for 6 sham and 7 lesioned rats in each group. ${ }^{*} \mathrm{P}<0.05$ compared to sham-lesioned rats (two-way ANOVA followed by the Tukey post hoc test). 
trols (7 days: $F_{1,44}=27.2, P<0.001 ; 15$ days: $F_{1,44}=4.4, P$ $<0.05$; Figure 3).

In a second group of rats we determined whether the lesions affected the intake of other solutions. Rats were allowed access for $2 \mathrm{~h} /$ day to $10 \%$ sucrose, a solution that is isosmotic with the body fluids. Sucrose intake in the

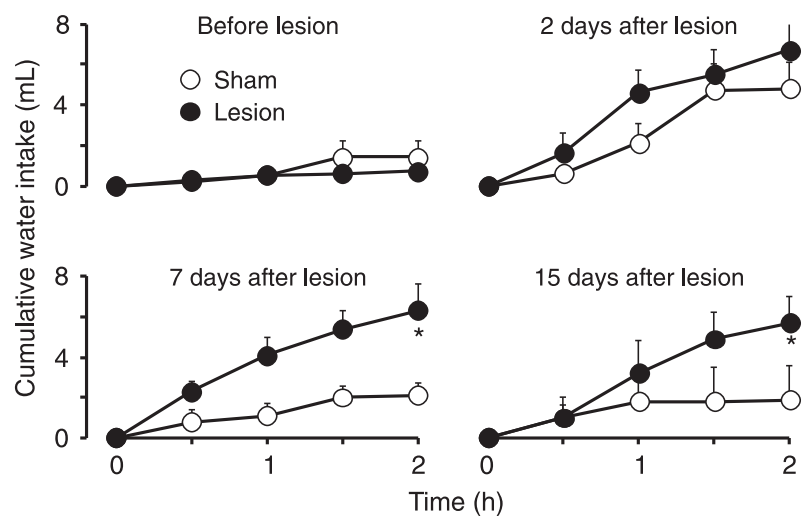

Figure 3. Cumulative water intake by sodium-depleted rats before surgery, and 2 days, 7 days, and 15 days after commissural nucleus of the tractus solitarius lesions or sham lesions. Data are reported as means \pm SEM for 6 sham and 7 lesioned rats in each group. ${ }^{*} P<0.05$ compared to sham-lesioned rats (two-way ANOVA followed by the Tukey post hoc test).

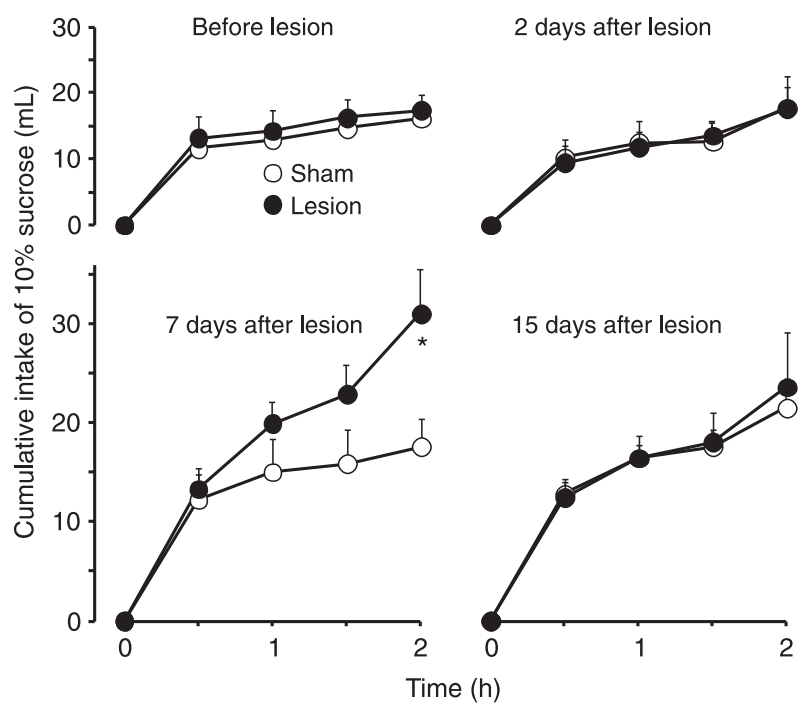

Figure 4. Cumulative $10 \%$ sucrose intake at $30,60,90$, and 120 min before surgery, and 2, 7, and 15 days after commissural nucleus of the tractus solitarius lesions or sham lesions. Data are reported as means \pm SEM for 5 sham and 5 lesioned rats in each group. ${ }^{*} \mathrm{P}<0.05$ compared to sham-lesioned rats (two-way ANOVA followed by the Tukey post hoc test). control and experimental groups was similar in the prelesion test. One week after the lesion, sucrose intake was significantly higher in lesioned than in sham-lesioned rats $\left(F_{1,32}=9.6, P<0.01\right)$, but this effect was not seen 2 days or 15 days after the lesion (Figure 4). Although the rats were allowed to drink water during the period of access to sucrose, they drank little $(<1 \mathrm{~mL})$, and water intake was similar in the lesioned and sham-lesioned groups.

\section{Discussion}

The present study showed that acute and chronic lesions of the commissural NTS enhanced sodium and water intake. The effect on sodium intake was rapid. Water intake was always low during the initial part of the sodium appetite test, and may well have been a consequence of increased tonicity of the gut or blood secondary to intake of hypertonic saline solution. Sucrose intake was increased 7 days after lesion, but not 2 and 15 days after lesion. Our data suggest that the lesions may impair gastrointestinal satiety signals, but we cannot yet rule out other mechanisms.

Both inhibitory and excitatory mechanisms affect sodium intake. Among the excitatory mechanisms are circulating angiotensin and aldosterone, which are released after sodium loss. It seems unlikely that lesioned rats lost more sodium than control rats during the depletion period because commissural NTS lesions do not increase blood pressure and in fact reduce blood pressure in spontaneously hypertensive rats (14-16), but we do not have data on changes in sodium balance and blood volume during the depletion period. It also seems less likely that increased sodium appetite in lesioned rats was due to aldosterone, because our lesions probably destroyed part of the aldosterone-sensitive neurons that are thought to stimulate sodium intake (17-20). Unfortunately we have no information on the effect of the lesions on plasma angiotensin levels and on the efficiency of angiotensin, but it has been shown recently that rats with chronic commissural NTS lesions overdrink in response to isoproterenol (21), a $\beta$-adrenergic agonist that stimulates an angiotensin-dependent thirst.

The lesions could also reduce inhibitory mechanisms. With respect to sodium appetite, gastrointestinal stretch may provide an important satiety signal (22). Earlier studies have suggested an inhibitory circuit for salt appetite that involves projections from the area postrema and NTS to the parabrachial nucleus (23). The lateral parabrachial nucleus can powerfully inhibit sodium intake $(1,2)$. It has been suggested that the increased intake of fluids in rats with area postrema lesions is caused by the lack of rapid 
feedback inhibition (3). We suggest that impairment of this mechanism mediates the increased sodium intake after commissural NTS lesions. Lack of feedback inhibition can also explain our finding that the lesions can stimulate the intake of sweet solutions, even though they reduce daily food intake (24). In addition it was recently reported that commissural NTS lesions stimulate the water intake induced by isoproterenol (21). Similar lesions do not increase daily water intake (24). All of these findings support the idea that rats with commissural NTS lesions lack the satiety signals that normally terminate a meal or a drinking bout. The commissural NTS receives dense projections from gastrointestinal afferents $(25,26)$, and these might be missing in lesioned rats. The NTS, and especially its more rostral areas, also receives gustatory primary afferents (26), and anterograde tracer studies have demonstrated that neurons within the rostral NTS project to the commissural NTS, to the parabrachial nucleus, and to the reticular formation $(27,28)$. However, changes in taste do not explain reduced daily food intake coupled to overdrinking of sucrose solution by lesioned rats. Unfortunately it is not yet known if commissural NTS lesions reduce need-free saline intake.

The commissural NTS is an important area for integration of chemoreceptor and aortic baroreceptor responses $(7,15,29)$. Lesions of the commissural NTS do not change basal arterial pressure in normotensive rats $(14,15)$, and therefore the increased sodium intake in lesioned rats in the present study was probably not due to reduced blood pressure. Lesions of the commissural NTS also acutely abolish chemoreceptor reflex responses, attenuate the reflex tachycardia evoked by sodium nitroprusside, and enhance the pressor response evoked by carotid occlusion $(14,15,30)$. However, baroreceptor denervation reduces need-induced sodium intake (31), suggesting that increased saline intake in commissural NTS-lesioned rats is not caused by impaired processing of arterial baroreceptor input.

Increased saline intake with commissural NTS lesions is surprising because it has been shown that lesions of the area postrema stimulate induced sodium intake, but larger lesions that include both the area postrema and the commissural NTS do not (4-6). Similarly, it has been reported that the inhibition of daily food intake induced by area postrema lesions is reduced if the lesions also include parts of the NTS (6), whereas lesions of only the commissural NTS greatly reduce daily food intake (24). The area postrema sends a prominent projection to the medial NTS (32), and at least a portion of this projection appears to inhibit NTS neurons (33). The medial NTS, in turn, projects to areas in the forebrain and hypothalamus that are known to be important for the control of body fluid homeostasis and ingestive behavior (3). Presumably the functional anatomy of this region is more complex than currently known.

Therefore, the major contribution of this study is that the commissural NTS constitutes part of the inhibitory pathway involved in sodium appetite control. This finding helps to elucidate part of the central integrative mechanisms involved in sodium appetite regulation.

\section{References}

1. Menani JV, De Luca LA Jr, Thunhorst RL, Johnson AK. Hindbrain serotonin and the rapid induction of sodium appetite. Am J Physiol Regul Integr Comp Physiol 2000; 279: R126-R131.

2. Callera JC, Oliveira LB, Barbosa SP, Colombari DS, De Luca LA Jr, Menani JV. GABA(A) receptor activation in the lateral parabrachial nucleus induces water and hypertonic $\mathrm{NaCl}$ intake. Neuroscience 2005; 134: 725-735.

3. Curtis KS, Verbalis JG, Stricker EM. Area postrema lesions in rats appear to disrupt rapid feedback inhibition of fluid intake. Brain Res 1996; 726: 31-38.

4. Contreras RJ, Stetson PW. Changes in salt intake lesions of the area postrema and the nucleus of the solitary tract in rats. Brain Res 1981; 211: 355-366.

5. Watson WE. The effect of removing area postrema on the sodium and potassium balances and consumptions in the rat. Brain Res 1985; 359: 224-232.

6. Wang T, Edwards GL. Differential effects of dorsomedial medulla lesion size on ingestive behavior in rats. Am J

Physiol 1997; 273: R1299-R1308.

7. Vardhan A, Kachroo A, Sapru HN. Excitatory amino acid receptors in commissural nucleus of the NTS mediate carotid chemoreceptor responses. Am J Physiol 1993; 264: R41-R50.

8. Hamilton RB, Norgren R. Central projections of gustatory nerves in the rat. J Comp Neurol 1984; 222: 560-577.

9. Travers SP, Norgren R. Organization of orosensory responses in the nucleus of the solitary tract of rat. $J$ Neurophysiol 1995; 73: 2144-2162.

10. Norgren R, Leonard CM. Taste pathways in rat brainstem. Science 1971; 173: 1136-1139.

11. Norgren R, Leonard CM. Ascending central gustatory pathways. J Comp Neurol 1973; 150: 217-237.

12. Kang $Y$, Yan J, Huang $T$. Microinjection of bicuculline into the central nucleus of the amygdala alters gustatory responses of the rat parabrachial nucleus. Brain Res 2004; 1028: 39-47.

13. Sato MA, Schoorlemmer GH, Menani JV, Lopes OU, 
Colombari E. Recovery of high blood pressure after chronic lesions of the commissural NTS in SHR. Hypertension 2003; 42: 713-718.

14. Colombari E, Menani JV, Talman WT. Commissural NTS contributes to pressor responses to glutamate injected into the medial NTS of awake rats. Am J Physiol 1996; 270: R1220-R1225.

15. Sato MA, Menani JV, Lopes OU, Colombari E. Commissural NTS lesions and cardiovascular responses in aortic baroreceptor-denervated rats. Hypertension 1999; 34: 739743.

16. Akemi Sato M, Vanderlei Menani J, Ubriaco Lopes O, Colombari E. Lesions of the commissural nucleus of the solitary tract reduce arterial pressure in spontaneously hypertensive rats. Hypertension 2001; 38: 560-564.

17. Geerling JC, Engeland WC, Kawata M, Loewy AD. Aldosterone target neurons in the nucleus tractus solitarius drive sodium appetite. J Neurosci 2006; 26: 411-417.

18. Geerling JC, Kawata M, Loewy AD. Aldosterone-sensitive neurons in the rat central nervous system. J Comp Neurol 2006; 494: 515-527.

19. Geerling JC, Loewy AD. Aldosterone-sensitive neurons in the nucleus of the solitary tract: bidirectional connections with the central nucleus of the amygdala. J Comp Neurol 2006; 497: 646-657.

20. Geerling JC, Loewy AD. Sodium depletion activates the aldosterone-sensitive neurons in the NTS independently of thirst. Am J Physiol Regul Integr Comp Physiol 2007; 292: R1338-R1348.

21. Blanch GT, Freiria-Oliveira AH, Colombari E, Menani JV, Colombari DS. Lesions of the commissural subnucleus of the nucleus of the solitary tract increase isoproterenol-induced water intake. Braz J Med Biol Res 2007; 40: 11211127.

22. Stricker EM, Hoffmann ML. Control of thirst and salt appetite in rats: early inhibition of water and $\mathrm{NaCl}$ ingestion. Appetite 2006; 46: 234-237.

23. Jhamandas $\mathrm{JH}$, Harris $\mathrm{KH}$. Influence of nucleus tractus solitarius stimulation and baroreceptor activation on rat parabrachial neurons. Brain Res Bull 1992; 28: 565-571.

24. Menani JV, Colombari E, Talman WT, Johnson AK. Com- missural nucleus of the solitary tract lesions reduce food intake and body weight gain in rats. Brain Res 1996; 740: 102-108.

25. Powley TL, Berthoud HR, Fox EA, Lhangton W. The dorsal vagal complex forms a sensory-motor lattice: the circuitry of gastrointestinal reflexes. In: Ritter S, Ritter RC, Barnes CD (Editors), Neuroanatomy and physiology of abdominal vagal afferents. Boca Raton: Oxford University Press; 1992. p 55-79.

26. Berthoud HR. The caudal brainstem and the control of food intake and energy balance. In: Stricker EM, Woods S (Editors), Neurobiology of food and fluid intake. Vol. 14. Handbook of behavioral neurobiology. 2nd edn. New York: Kluwer Academic/Plenum Publishers; 2004. p 195-240.

27. Herbert H, Moga MM, Saper CB. Connections of the parabrachial nucleus with the nucleus of the solitary tract and the medullary reticular formation in the rat. $J$ Comp Neurol 1990; 293: 540-580.

28. Halsell CB, Travers SP, Travers JB. Ascending and descending projections from the rostral nucleus of the solitary tract originate from separate neuronal populations. Neuroscience 1996; 72: 185-197.

29. Chitravanshi VC, Kachroo A, Sapru HN. A midline area in the nucleus commissuralis of NTS mediates the phrenic nerve responses to carotid chemoreceptor stimulation. Brain Res 1994; 662: 127-133.

30. Sato MA, Menani JV, Lopes OU, Colombari E. Enhanced pressor response to carotid occlusion in commNTS-lesioned rats: possible efferent mechanisms. Am J Physiol Regul Integr Comp Physiol 2000; 278: R1258-R1266.

31. Thunhorst RL, Morris M, Johnson AK. Endocrine changes associated with a rapidly developing sodium appetite in rats. Am J Physiol 1994; 267: R1168-R1173.

32. Shapiro RE, Miselis RR. The central neural connections of the area postrema of the rat. J Comp Neurol 1985; 234: 344-364

33. Kachidian P, Pickel VM. Localization of tyrosine hydroxylase in neuronal targets and efferents of the area postrema in the nucleus tractus solitarii of the rat. J Comp Neurol 1993; 329: 337-353. 